\begin{tabular}{|c|c|c|c|c|}
\hline \multirow[t]{8}{*}{$\begin{array}{l}\text { Functional } \\
\text { constipation }\end{array}$} & \multirow[t]{8}{*}{$\begin{array}{l}9 / 4 \\
(20.6)\end{array}$} & Constipation & $\begin{array}{l}9 \\
(69.2)\end{array}$ & $\begin{array}{l}\text { Dietary review/ } \\
\text { modification } 4\end{array}$ \\
\hline & & GOR & $1(7.7)$ & Stool softener/laxative 4 \\
\hline & & Cow's milk allergy & $1(7.7)$ & Symptom/stool diary 2 \\
\hline & & Abdominal pain & $1(7.7)$ & PPI 1 \\
\hline & & Possible polyp & $1(7.7)$ & Probiotic 1 \\
\hline & & & & Rifaximin 1 \\
\hline & & & & Anal sphincter Botox \\
\hline & & & & injection 1 \\
\hline \multirow{10}{*}{$\begin{array}{l}\text { Functional } \\
\text { dyspepsia }\end{array}$} & \multirow{10}{*}{$\begin{array}{l}9 / 0 \\
(14.3)\end{array}$} & IBS & 3 & Dietary review/ \\
\hline & & & (33.3) & modification 5 \\
\hline & & GOR & 3 & PPI 3 \\
\hline & & & (33.3) & Anti-spasmodic 1 \\
\hline & & Oesophagitis & 1 & \\
\hline & & & $(11.1)$ & \\
\hline & & Nausea, early & 1 & \\
\hline & & satiety & $(11.1)$ & \\
\hline & & Non-specific & 1 & \\
\hline & & symptoms & $(11.1)$ & \\
\hline \multirow{8}{*}{$\begin{array}{l}\text { Functional } \\
\text { vomiting }\end{array}$} & \multirow[t]{8}{*}{$5 / 0(7.9)$} & Oesophagitis & $1(20)$ & PPI 3 \\
\hline & & IBS & $1(20)$ & Symptom diary 1 \\
\hline & & Intermittent & $1(20)$ & Dietary review/ \\
\hline & & vomiting & & modification 1 \\
\hline & & Chronic nausea & $1(20)$ & Psychological therapy/ \\
\hline & & None given & $1(20)$ & review 1 \\
\hline & & & & Laxative 2 \\
\hline & & & & Anti-diarrhoeal 1 \\
\hline \multirow[t]{6}{*}{ FAP-NOS } & \multirow[t]{6}{*}{$3 / 0(4.8)$} & Constipation & 1 & Dietary review/ \\
\hline & & & (33.3) & modification 3 \\
\hline & & IBS & 1 & Stool diary 1 \\
\hline & & & (33.3) & Laxative 1 \\
\hline & & None given & 1 & \\
\hline & & & (33.3) & \\
\hline \multirow[t]{2}{*}{ CVS } & \multirow[t]{2}{*}{$2 / 0(3.2)$} & Cyclic vomiting & $1(50)$ & Laxative 2 \\
\hline & & $\begin{array}{l}\text { Abdominal pain, } \\
\text { vomiting }\end{array}$ & $1(50)$ & \\
\hline Rumination & $1 / 1(3.2)$ & Rumination & $2(100)$ & None 2 \\
\hline syndrome & & syndrome & & \\
\hline \multirow{3}{*}{$\begin{array}{l}\text { Abdominal } \\
\text { migraine }\end{array}$} & \multirow[t]{3}{*}{$0 / 1(1.6)$} & \multirow[t]{3}{*}{ Abdominal migraine } & \multirow[t]{3}{*}{$1(100)$} & Dietary review/ \\
\hline & & & & modification 3 \\
\hline & & & & Anti-spasmodic 1 \\
\hline \multirow[t]{2}{*}{ Functional nausea } & \multirow[t]{2}{*}{$1 / 0(1.6)$} & Nausea and early & $1(100)$ & Dietary review/ \\
\hline & & satiety & & modification 1 \\
\hline
\end{tabular}

IBS: Irritable Bowel Syndrome

FAP-NOS: Functional abdominal pain - not otherwise specified

CVS: Cyclic vomiting syndrome

GOR: Gastroesophageal reflux

PPI: proton pump inhibitor

reviewed. Patients were classified according to the Rome IV criteria and diagnoses assigned following clinical assessment, investigations, and follow-up, and clinical management, were recorded.

Results In total, 53/228 (27.6\%) children had an FGID according to the Rome IV criteria. Sufficient information was available to make a definite FGID diagnosis using the Rome IV criteria in $44(83.0 \%)$ cases. The most common diagnoses were IBS $(27 ; 42.9 \%)$ and functional constipation (13; 20.6\%); 10 children (18.9\%) had two FGIDs. Clinical diagnoses and clinical management varied markedly within each Rome IV diagnosis (table 1).

Conclusion Use of the Rome IV criteria in routine practice is achievable and would likely better capture the clinical burden of these common conditions through greater consistency in clinical diagnosis. In addition, use of the criteria would encourage quality improvement projects and research to better inform clinical management.

\section{P17 DO NAFLD PATIENTS ENGAGE WITH ADDITIONAL WEIGHT MANAGEMENT SUPPORT BETWEEN APPOINTMENTS?}

${ }^{1}$ Helen Mortimer, ${ }^{1}$ Sara Mancell, ${ }^{2}$ Emer Fitzpatrick. ${ }^{1}$ King's College Hospital; ${ }^{2}$ King's Liver Centre

\subsection{6/flgastro-2021-bspghan.27}

Background and Aim With the exponential increase in diagnosis of non-alcoholic fatty liver disease (NAFLD) in children and young people (CYP) in the UK, the numbers of CYP attending tertiary NAFLD clinics continues to rise. Though there is no convincing evidence that pharmacological therapy can halt or reverse disease, there is strong evidence that $5-10 \%$ weight loss can improve or reverse the condition. From a liver surveillance perspective, appointments with bloods and imaging every 6-12 months are deemed sufficient, but are not adequate to support diet and lifestyle changes. The purpose of this study was to determine whether patients and their parents/carers engaged with input between appointments, and whether it improved weight loss.

Subjects and Methods All patients who attended NAFLD clinic requiring weight management support (January - August 2018) were offered follow up between appointments. A phone call or email was sent within six weeks of the appointment. Where phone calls were unanswered a message was left, and a letter sent if no answering service. If there was no response, no further contact attempts were made. Clinical, biochemical and anthropometric data were collected on all CYP who attended clinic; patients were reviewed 6-12 monthly. Diagnosis of NAFLD was made by paediatric hepatologist with biopsy or a combination of radiological and biochemical data on exclusion of all other known causes of liver disease. CYP were excluded if they attended another dietetic service regularly, were achieving sufficient weight loss, or weight management was not the primary reason for review. Body mass index (BMI) was calculated and converted to z-scores (WHO criteria).

Results During the study period 33 CYP $(11 \mathrm{~F})$ were offered additional follow up; all agreed. Mean (SD) age was 15.0 (2.15) years at initial appointment. A phone call was requested by $17(52 \%)$ and $16(48 \%)$ preferred email. Contact was made with the parent/carer in 19 cases (58\%) and 14(42\%) directly with the CYP. Contact was made with 15(45\%), nine (60\%) by phone and six (40\%) by email. Of those who received additional follow up five (33\%) had a second contact and one (3\%) a third contact. Mean (SD) follow up time was 37.9 (2.41) weeks. For the $24(73 \%)$ patients with both initial and follow up data, mean (SD) BMI z-score at initial appointment was $3.19(0.53)$ and follow up 3.23(0.62). There was no difference between responders/non-responders in BMI z-score change.

Summary and Conclusions Although all the CYP agreed to have additional follow up, only $45 \%$ responded. The preference for contact was via phone and with parent/carer. A limitation was that only one attempt was made to reach each 
patient; messages may not have been received. As the initial response to more regular follow up was positive, consideration should be made to whether a pre-arranged phone clinic would be more suitable. Future research could focus on reasons why $\mathrm{CYP} /$ their families are reluctant to engage, and ways to empower CYP to change.

To pave the way forward a patient questionnaire evaluating the current service and seeking opinions regarding regular, remote follow up would be valuable.

\section{P18 EFFECTIVENESS OF HOME BOWEL PREPARATION FOR CHILDREN LIVING LONG DISTANCES FROM ENDOSCOPY CENTRE}

Jamie Motion, Malcolm Sutherland, Brenda Smart, Carol Cameron, Shyla Kishore, lain Chalmers, Su Bunn. NHS Grampian

\subsection{6/flgastro-2021-bspghan.28}

Introduction The North of Scotland Paediatric Gastroenterology, Hepatology and Nutrition Network (NoSPGHANN) manages children over an area of $53,000 \mathrm{~km}^{2}$. Travel distances to Royal Aberdeen Children's Hospital (RACH) were previously felt to preclude the adoption of home bowel preparation (HBP) for elective colonoscopies but a trial period of HBP commenced in March 2020. The same drugs (senna and Picolax) were used for inpatient bowel preparation (IPBP) or HBP but the timings were changed for HBP to complete all doses on the day prior to procedure to allow travel to RACH. This audit evaluates the impact of this change of practice.

Methods All children undergoing elective colonoscopy at RACH between December 2019 and November 2020 were identified. Electronic were records reviewed to determine IPBP vs HBP, distance to RACH from patient's home, bowel preparation score, morning or afternoon list, requirement for intravenous (IV) fluids during the procedure, day case procedure and length of stay. Bowel preparation score was derived from the Aronchick Scale and converted as follows: 0 (unacceptable), 1 (poor), 2 (fair), 3 (good) and 4 (excellent).

Results

Summary The high standard of bowel preparation achieved with IPBP was maintained when delivered at home, despite some children travelling $>100$ miles and having travelling times of $>3$ hours. Delivering all doses of drugs on the day before procedure did not affect the quality of bowel preparation for afternoon lists. There is a trend to a higher proportion of children with HBP receiving IV fluids during anaesthetic which may suggest that some are dehydrated. The proportion of day case procedures has increased from $0 \%$ to 72\%, which since March 2020, has saved NHS Grampian $£ 18,000$.

Conclusion Home bowel preparation delivered on day prior to procedure is well tolerated and as effective as inpatient delivered, even for children with long travelling times to hospital. Covid-19 distancing measures have reduced the number of available inpatient beds so HBP has aided bed management in addition to providing a cost saving. The risk of dehydration may be higher for HBP and guidance will be changed to increase the emphasis on oral fluid intake, including during travelling time, on day of procedure.

\section{P19 EFFICACY OF THIOPURINES IN PREVENTING INFLIXIMAB ANTIBODY FORMATION WHEN USED IN DUAL THERAPY: EXPERIENCE FROM A SINGLE TERTIARY PAEDIATRIC GASTROENTEROLOGY DEPARTMENT}

Muhamad Azim Muhamad Amin, Varsha Datta, Danica Hapuarachchi, Loveday Jago, Andrew Fagbemi, Ahmed Kadir. Royal Manchester Children Hospital, Manchester

\subsection{6/flgastro-2021-bspghan.29}

Background and Aim There is evidence that shows addition of an immunomodulator (azathioprine or mercaptopurine) to Infliximab (IFX) therapy reduces antidrug antibodies, however, published evidence remains quite limited in paediatric population. We conducted a review to observe whether there is any correlation between the drug level of azathioprine metabolites, that is 6-thioguanine nucleotides (6-TGN) and development of anti-IFX antibodies (Abs) in inflammatory bowel disease (IBD) patients.

Method This is a retrospective study of patients with IBD based on a single tertiary paediatric gastroenterology department that had their levels monitored from March 2016 until March 2020. We defined maximum drug efficacy based on consensus on ESPGHAN management of IBD in paediatric and our lab references $(235-450 \mathrm{pmol} / 8 \times 108)$. In order to maintain consistencies, we included patients on 8 weekly 5 $\mathrm{mg} / \mathrm{kg}$ of Infliximab infusion regimen who had their azathioprine metabolites measured within 3 months from starting. Fishers test and Pearson correlation were used to test the correlation between the drug level of azathioprine metabolites and development of IFX Abs.

Results $36(58 \%)$ out of 62 patients were included in this study based on the above criteria (median age 14.25). Mean level of 6-TGN was lower in anti-IFX Abs-positive patients compared to anti-IFX Abs-negative patients (316.2 vs 322.8) with $6.607 \pm 57.51$ (CI $-123.5-110.3, \mathrm{p}=0.91)$. There is a positive correlation between positive Anti-IFX abs with lower level of Azathioprine metabolites with coefficient at 0.47 $(\mathrm{p}=0.05)$.

Conclusion Our data demonstrates there is positive correlation between lower levels of azathioprine metabolites and positive anti-IFX abs level, hence suggestive of the importance of adherence to treatment to ensure longevity usage infliximab in IBD patients.

\section{P20 EMERGENCI: A UK PROSPECTIVE SURVEY OF SEVERE GI BLEEDING (REQUIRING UPPER GI ENDOSCOPY) AND EMERGENCY ENDOSCOPY IN UNDER 16S}

${ }^{1}$ Natasha Thorn, ${ }^{1}$ Martina Vallorani, ${ }^{1}$ Ramiya Kirupananthan, ${ }^{2}$ Polychronis Kemos, ${ }^{2}$ Nicholas Croft. 'Paediatric Gastroenterology, Royal London Children's Hospital, Barts Health NHS Trust, London; ${ }^{2}$ Blizard Institute, Barts and the London School of Medicine, Queen Mary University of London

\subsection{6/flgastro-2021-bspghan.30}

Objectives EMERGENCi is a prospective, national, cohort study of emergency endoscopy and severe upper GI bleeds in children. Objectives were to produce national data of the clinical presentations, patient co-morbidities, indications, waiting times and endoscopic treatments for emergency endoscopy. Methods Units were identified through the UK Paediatric Gastroenterology and Paediatric Surgical Societies (BSPGHAN \& BAPS). Once registered, fortnightly emails were sent over a 6 month period asking for reports in $<16$ years of severe upper 